\title{
Comparison of the Efficacy of Oral Oxycodone and Oral Codeine in the Treatment of Post-Craniotomy Pain-A Randomized, Double-Blind Trial
}

\author{
Rui Min Lee*, Beatrice C. L. Lim, Chin Ted Chong, Mandy P. P. Lim \\ Department of Anaesthesiology, Intensive Care and Pain Medicine, Tan Tock Seng Hospital, Singapore \\ Email: ${ }^{\star R u i}$ min_lee@ttsh.com.sg
}

How to cite this paper: Lee, R.M., Lim, B.C.L., Chong, C.T. and Lim, M.P.P. (2020) Comparison of the Efficacy of Oral Oxycodone and Oral Codeine in the Treatment of Post-Craniotomy Pain-A Randomized, Double-Blind Trial. Open Journal of Anesthesiology, 10, 80-88.

https://doi.org/10.4236/ojanes.2020.103007

Received: January 14, 2020

Accepted: March 15, 2020

Published: March 18, 2020

Copyright $\odot 2020$ by author(s) and Scientific Research Publishing Inc. This work is licensed under the Creative Commons Attribution International License (CC BY 4.0).

http://creativecommons.org/licenses/by/4.0/

\begin{abstract}
Background: Post-craniotomy pain has been reported to be moderate to severe. Management of post-craniotomy pain is often inadequate, yet limited by the side effects of opioids. We aim to find out the efficacy of oral oxycodone as compared to oral codeine for the treatment of post-craniotomy pain in our institution. Methods: A randomized, double-blinded controlled trial was used to evaluate the efficacy of oral oxycodone versus oral codeine. 40 patients were randomized to the control group of codeine $(n=20)$ or the experimental group receiving oxycodone $(n=20)$ in addition to regular oral paracetamol for both groups of patients. Results: There was no difference in the visual analogue scale scores at 24 hours ( 2.78 versus $1.85, \mathrm{p}=0.11$ ) or side effects in the oxycodone group compared with the codeine group. Conclusions: Oral oxycodone had similar efficacy as oral codeine in the management of post-craniotomy pain.
\end{abstract}

\section{Keywords}

Post-Craniotomy Pain, Oxycodone, Codeine

\section{Introduction}

Non-opioids have been the mainstay of treatment for post craniotomy pain due to the fear of side effects associated with opioids and the assumption that craniotomies were not painful procedures [1] [2]. Side effects of opioids such as sedation may interfere with accurate neurological monitoring postoperatively resulting in the masking of intracranial catastrophes; nausea and vomiting can 
cause an increase in intracranial pressure while depression of minute ventilation can lead to hypercapnia causing vasodilatation of intracerebral blood vessels with potential raised intracranial pressure as well.

On the other hand, post-craniotomy pain has been reported to be moderate to severe in $80 \%$ of patients [1], and may persist for several days, in which case non-opioids may not be adequate to treat such pain. Failure to treat severe pain can cause increased blood pressure with resultant increased intracranial pressure in addition to increased risk of intracranial bleeding. There have been multiple studies done to assess the efficacy and safety of opioids using various routes of administration in post craniotomy pain. Morphine was found to offer improved analgesia with no significant increase in adverse events compared to codeine [1], although most trials were not sufficiently powered to detect a difference.

Patient controlled analgesia (PCA) morphine versus PCA oxycodone has also been studied for the control of postoperative pain in various operations such as abdominal surgeries or bone fractures and they were found to be comparable in terms of analgesic as well as side effect profiles [3] [4]. Tanskanen found that PCA oxycodone for post craniotomy pain was effective when supplemented with either oral paracetamol or ketoprofen and the median dose required was $19.6 \mathrm{mg}$ to $37.1 \mathrm{mg}[5]$.

In view of the purported better analgesic efficacy and side effect profile of oxycodone over codeine, we thus undertook this randomized controlled, double blind trial in 40 patients to find out the efficacy of oral oxycodone compared to oral codeine for the treatment of post-craniotomy pain in our local population in a single institution. Oral forms of both analgesics were chosen to account for the onset of action.

\section{Methods}

This randomised, double blinded study was approved by the local Ethics Committee and registered with ClinicalTrials.gov (ref: NCT01672112). 40 patients were recruited for the study. Permission for use of oxycodone in neurosurgical patients was obtained from the Health Sciences Authority, Singapore. Patients were recruited preoperatively before arrival in the operating theatre.

The study was performed between August 2012 and September 2014. Study participants were ASA 1 - 3 adults aged 21 to 70 years old who were undergoing craniotomies for various elective neurosurgical procedures including tumour resection and aneurysm clipping. Patients had to be able to understand and use the visual analogue scale for pain and nausea assessment.

Patients were excluded if their Glasgow Coma Scale was less than 15, if they had renal or hepatic impairment as evidenced by raised creatinine or deranged liver function tests. Other exclusion criteria were: inability to quantify pain according to VAS scale, patients who would be kept intubated postoperatively, any contraindications or allergies to paracetamol or study drugs, patients with postoperative cognitive impairment and patients with decreased respiratory reserves. 
Written informed consent was obtained from each patient in a protocol approved by the institutional review board of Tan Tock Seng Hospital prior to scheduled surgery. No interim analysis was performed.

\section{Randomisation}

Patients were randomly assigned to receive either codeine or oxycodone postoperatively on a background of regular oral paracetamol $1 \mathrm{~g} 6$ hourly. Block randomisation was done via a computer generated code. The investigators and nurse in charge of the patient were aware of the patients' group assignment but the patients, attending anaesthetists and postoperative assessors were not. When surgery was over and the patient successfully extubated, the attending anaesthetist would call the primary investigator who would then open the sequentially numbered, opaque sealed envelope assigned to the patient. The primary investigator would then key in the assigned drug into the patient's computerised drug chart. Randomisation occurred only after surgery when patient was included into the trial, having determined that he had met all inclusion criteria. The nurse directly looking after the patient was responsible for administering the assigned analgesia and was not blinded. The assessors assessing the patients for pain VAS score, sedation score based on the TTSH acute pain service sedation score, GCS level, respiratory rate, nausea and vomiting, satisfaction score were blinded and could not access the patient's computerised drug chart.

\section{Procedure}

The choice of maintenance of general anaesthesia whether with inhalational or total intravenous anaesthesia was left to the discretion of the attending anaesthetist. Intraoperative analgesia for the patients was limited to remifentanil infusions and fentanyl boluses up to $2 \mathrm{mcg} / \mathrm{kg}$; morphine was not used. As per standard hospital protocol, local anaesthesia consisting of $10 \mathrm{ml}$ 0.5\% bupivacaine and $10 \mathrm{ml} 1 \%$ lignocaine with adrenaline 1:400,000 was infiltrated by the surgeon prior to skin incision. Routine antiemetic prophylaxis of intravenous ondansetron $4 \mathrm{mg}$ was given at the end of surgery. Data regarding the intraoperative use of anti-emetics, anti-epileptics, doses of remifentanil and local anaesthesia used as well as the dose and point of administration of fentanyl were recorded. Pertaining to the surgery, data was collected in terms of the site of surgery and presence of headache preoperatively. The patients were operated on by various neurosurgical surgeons in our hospital.

Patients were sent to neurosurgery high dependency ward postoperatively and then either continued their stay there or were discharged to a neurosurgical ward on subsequent days. They were reviewed from postoperative day (POD) 0 to 3 by blinded assessors with the assessment of pain scores using visual analogue scales ( 0 being no pain and 10 being the worst possible pain), conscious level using the Glasgow Coma Scale and sedation score, adverse events in terms of nausea and vomiting, respiratory depression and sedation. In addition, patient 
satisfaction was assessed at the end of day 1 and 3 .

Patients received regular oral paracetamol 1 gram 6 hourly and intravenous ondansetron $4 \mathrm{mg} 8$ hourly as required for the first 3 days postoperatively. For the codeine group, oral codeine was ordered as $60 \mathrm{mg} 6$ hourly as required while for the oxycodone group, oral oxycodone was ordered as $5 \mathrm{mg} 6$ hourly as required. $5 \mathrm{mg}$ oral oxycodone is approximately equipotent to $60 \mathrm{mg}$ oral codeine. The patient received oral codeine or oxycodone depending on the assigned group if he or she had a pain score of more than 4.1 hour later, VAS was reassessed and if pain score was still more than 4, another dose of opioid would be given. In the event of unresolved pain after an oral opioid, with the patient having a pain score of more than 4 within 6 hours, the medical officer in neurosurgery high dependency was called by the nurse to serve intravenous fentanyl 20 mcg boluses up to $100 \mathrm{mcg}$.

\section{Outcomes}

The primary outcomes were: 1 ) incidence of severe pain (defined as visual analogue scores (VAS) > 5) and 2) difference in the mean pain VAS scores in both groups at 24 hours. Secondary outcomes were: 1) differences in the mean pain VAS scores at 48 and 72 hrs post-operatively; 2) incidence of excessive sedation with sedation score of more than 2 based on the TTSH acute pain service sedation score, depression of respiratory rate less than 10 and GCS between the 2 groups and 3) mean patient satisfaction scores at 24 and $72 \mathrm{hrs}$.

\section{Statistical Analysis}

Considering a difference in mean pain VAS scores of 2 to be clinically significant, 40 patients would be required for a 2 group study with an $80 \%$ power of detecting a difference and a type 1 error of $5 \%$.

All patients were followed up completely for 3 postoperative days and reported results are therefore based on all completed cases without imputation for missing data.

Continuous variables were presented as mean (standard deviation) or median (interquartile range) after assessing for normality. Categorical variables were summarized using frequency (percentages). Differences in proportions (\%) between 2 groups were tested using chi square or Fishers exact test for categorical outcome variables. Depending on the normality of continuous outcome variables, independent student $t$ test or Mann Whitney $U$ test were conducted to compare 2 groups. One way analysis of variance or Kruskal Wallis test were used for comparing the groups at different time points. The primary analysis included all patients who completed the study. All statistical analyses were performed using SPSS v19. Significance level was set at $\mathrm{p} \leq 0.05$.

\section{Results}

48 patients were screened and 8 were excluded. Amongst the excluded patients, 
7 did not meet inclusion criteria and 1 patient was found preoperatively to show signs of confusion due to the brain tumour resulting in inability to retain information. 40 patients were then randomized equally to either the codeine or the oxycodone group. Both codeine and oxycodone groups were similar in terms of age, gender, anaesthetic technique and doses of analgesics used intraoperatively (Table 1).

In the codeine (control) arm, 2 patients dropped out from the trial. 1 was re-intubated 18 hours postoperatively due to bilateral vocal cord paresis and another developed cerebral oedema on POD 1 requiring re-opening.

In the oxycodone (trial) arm, 2 patients also dropped out. 1 developed cerebral haematoma with drop in GCS on POD 2 hence was unable to assess pain scores accurately while another patient had reoperation for residual tumour on MRI scan on POD 2 (flow diagram).

There was no incidence of pain $>5$ in either group from POD 0 - 3. Mean VAS scores in both groups were similar at 24, 48 and 72 hours and not clinically significant. In both groups, the total cumulative dose of analgesics used was comparable and statistically insignificant at 24, 48 and 72 hours. Incidence of breakthrough pain requiring IV fentanyl was low at the various time points and comparable between the 2 groups (Table 2). Regardless of the site of surgery, pain scores were similar and not statistically significant (Table 3 ).

Table 1. Patient characteristics.

\begin{tabular}{|c|c|c|c|}
\hline \multirow{2}{*}{ Characteristics } & \multicolumn{2}{|c|}{ Treatment group } & \multirow{2}{*}{ p-value } \\
\hline & Codeine & Oxycodone & \\
\hline Age, mean \pm SD (years) & $52.56( \pm 11.07)$ & $45.53( \pm 11.82)$ & 0.06 \\
\hline Gender, Female (\%) & $14(70.0 \%)$ & $10(50.0 \%)$ & 0.197 \\
\hline Weight, mean \pm SD $(\mathrm{kg})$ & $62.20( \pm 14.96)$ & $63.28( \pm 12.16)$ & 0.804 \\
\hline \multicolumn{4}{|l|}{ ASA, n (\%) } \\
\hline 1 & $1(5.0 \%)$ & $0(0.0 \%)$ & \\
\hline 2 & $13(65.0 \%)$ & $14(70.0 \%)$ & \\
\hline 3 & $6(30.0 \%)$ & $6(30.0 \%)$ & \\
\hline Pain present, n (\%) & $5(25.0 \%)$ & $2(10.0 \%)$ & 0.407 \\
\hline \multicolumn{4}{|l|}{ Operative Site (\%) } \\
\hline Frontal & $7(35.0 \%)$ & $5(26.32 \%)$ & \\
\hline Occipital & $3(15.0 \%)$ & $3(15.79 \%)$ & \\
\hline Temporoparietal & $10(50.0 \%)$ & $11(57.89 \%)$ & \\
\hline \multicolumn{4}{|l|}{ Mode Of Anaesthesia (\%) } \\
\hline TIVA & $6(30.0 \%)$ & $8(40.0 \%)$ & 0.507 \\
\hline Volatile Agent & $14(70.0 \%)$ & $12(60.0 \%)$ & \\
\hline LA by Surgeon (\%) & $20(100.0 \%)$ & $19(95.0 \%)$ & 1.000 \\
\hline $\begin{array}{l}\text { Total Fentanyl Used, } \\
\text { mean } \pm \text { SD (mcg) }\end{array}$ & $133.75( \pm 60.30)$ & $135.00( \pm 57.01)$ & 0.947 \\
\hline $\begin{array}{l}\text { Total Remifentanil Used, } \\
\text { Median (IQR) (mcg) }\end{array}$ & $805(659-1507.5)$ & $787(600-1342.5)$ & 0.892 \\
\hline $\begin{array}{l}\text { Operative Duration, } \\
\text { mean } \pm S D(\text { min })\end{array}$ & $254.00( \pm 86.09)$ & $287.75( \pm 95.60)$ & 0.248 \\
\hline
\end{tabular}


Table 2. Pain score and corresponding amount of opiates used.

\begin{tabular}{|c|c|c|c|c|}
\hline & & \multicolumn{2}{|c|}{ Treatment } & \multirow{2}{*}{ p-value } \\
\hline & & Codeine & Oxycodone & \\
\hline \multirow{3}{*}{$\begin{array}{c}\text { Mean pain score, } \\
\text { mean } \pm S D\end{array}$} & $24 \mathrm{hrs}$ & $1.85 \pm 1.60$ & $2.78 \pm 1.92$ & 0.110 \\
\hline & $48 \mathrm{hrs}$ & $1.72 \pm 2.24$ & $2.72 \pm 1.97$ & 0.164 \\
\hline & $72 \mathrm{hrs}$ & $1.35 \pm 1.77$ & $2.33 \pm 2.06$ & 0.141 \\
\hline \multirow{3}{*}{$\begin{array}{l}\text { Total cumulative dose (all } \\
\text { converted to Oxycodone } \\
\text { dose in mg), median } \\
\text { (IQR) }\end{array}$} & $24 \mathrm{hrs}$ & $5(5-15)$ & $7.5(1.25-20)$ & 0.579 \\
\hline & $48 \mathrm{hrs}$ & $5(5-18.75)$ & $10(1.25-33.75)$ & 0.344 \\
\hline & $72 \mathrm{hrs}$ & $7.5(5-21.88)$ & $15(5-42.5)$ & 0.232 \\
\hline \multirow{3}{*}{$\begin{array}{l}\text { Number of Doses of } \\
\text { rescue IV fentanyl used, } \\
\text { n (\%) }\end{array}$} & $24 \mathrm{hrs}$ & $4(20.0)$ & $3(15.0)$ & 1.000 \\
\hline & $48 \mathrm{hrs}$ & $0(0.0)$ & $1(5.0)$ & 1.000 \\
\hline & $72 \mathrm{hrs}$ & $4(20.0)$ & $3(15.0)$ & 1.000 \\
\hline \multirow{2}{*}{$\begin{array}{l}\text { Patient satisfaction } \\
\text { scores, mean } \pm S D\end{array}$} & $24 \mathrm{hrs}$ & $7.71 \pm 2.05$ & $7.27 \pm 2.09$ & 0.566 \\
\hline & $72 \mathrm{hrs}$ & $8.17 \pm 1.40$ & $7.71 \pm 1.61$ & 0.431 \\
\hline
\end{tabular}

Table 3. Pain scores based on site of surgery.

\begin{tabular}{|c|c|c|c|c|c|c|c|c|}
\hline & & \multicolumn{6}{|c|}{ Site of surgery } & \multirow{3}{*}{ p-value } \\
\hline & & \multicolumn{2}{|r|}{ Frontal } & \multicolumn{2}{|c|}{ Occipital } & \multicolumn{2}{|c|}{ Temporoparietal } & \\
\hline & & $\mathrm{n}$ & mean $\pm S D$ & $\mathrm{n}$ & mean $\pm S D$ & $\mathrm{n}$ & mean $\pm S D$ & \\
\hline $\begin{array}{c}\text { Mean pain } \\
\text { VAS }\end{array}$ & $24 \mathrm{hrs}$ & 11 & $2.63 \pm 1.98$ & 6 & $2.60 \pm 1.78$ & 21 & $2.03 \pm 1.80$ & 0.623 \\
\hline score & $72 \mathrm{hrs}$ & 10 & $2.10 \pm 2.23$ & 6 & $1.67 \pm 2.25$ & 18 & $1.89 \pm 1.81$ & 0.915 \\
\hline
\end{tabular}

Side effect profiles were similar in both groups. No patient developed respiratory depression (respiratory rate $<10$ ) in either group (Table 4 ). There was no statistically significant difference in sedation scores, incidence of nausea and vomiting or GCS scores in both groups of patients as well (Table 4).

There were no statistically significant difference at 24 and 72 hours in terms of patient satisfaction scores, with a mean of 7.71 for codeine and 7.27 for oxycodone at 24 hours; and 8.17 and 7.71 for codeine and oxycodone respectively at 72 hours (Table 2).

In summary, there was no difference in the VAS scores between the codeine and oxycodone groups from POD 0 to 3 . The rates of adverse events were also similar.

\section{Discussion}

In our study, there was no difference in the use of oral codeine or oxycodone for the control of postoperative pain in our post-craniotomy patients. This is in contrast to many of the previous studies done [5] [6] and may be attributed to: lower pain scores in the local population and the pharmacokinetic profile of either drug in the local population. 
Table 4. Incidence of adverse events.

\begin{tabular}{|c|c|c|c|c|}
\hline & & \multicolumn{2}{|c|}{ Treatment } & \multirow{2}{*}{ p-value } \\
\hline & & Codeine & Oxycodone & \\
\hline \multirow{3}{*}{$\begin{array}{c}\text { Sedation scores at } \\
24 \mathrm{hrs}, \mathrm{n}(\%)\end{array}$} & 0 & $16(88.89)$ & $17(89.47)$ & 1.000 \\
\hline & 1 & $1(5.56)$ & $2(10.53)$ & \\
\hline & 2 & $1(5.56)$ & $0(0.00)$ & \\
\hline \multirow{3}{*}{$\begin{array}{c}\text { Sedation scores at } \\
48 \mathrm{hrs}, \mathrm{n}(\%)\end{array}$} & 0 & $15(83.33)$ & $18(100.00)$ & 0.229 \\
\hline & 1 & $2(11.11)$ & $0(0.00)$ & \\
\hline & 2 & $1(5.56)$ & $0(0.00)$ & \\
\hline \multirow{3}{*}{$\begin{array}{c}\text { Sedation scores at } \\
72 \mathrm{hrs}, \mathrm{n}(\%)\end{array}$} & 0 & $16(94.12)$ & $17(94.44)$ & 1.000 \\
\hline & 1 & $0(0.00)$ & $1(5.56)$ & \\
\hline & 2 & $1(5.88)$ & $0(0.00)$ & \\
\hline \multirow{3}{*}{$\begin{array}{l}\text { Respiratory rates, } \\
\text { mean } \pm \mathrm{SD}\end{array}$} & $24 \mathrm{hrs}$ & $15.25 \pm 6.45$ & $16.53 \pm 3.60$ & 0.453 \\
\hline & $48 \mathrm{hrs}$ & $15.55 \pm 5.726$ & $16.28 \pm 2.782$ & 0.628 \\
\hline & $72 \mathrm{hrs}$ & $13.50 \pm 7.193$ & $15.89 \pm 2.423$ & 0.175 \\
\hline \multirow{3}{*}{$\%$ GCS (14 or 15$)$} & $24 \mathrm{hrs}$ & $18(100 \%)$ & $19(100 \%)$ & NA \\
\hline & $48 \mathrm{hrs}$ & $18(100 \%)$ & $18(100 \%)$ & NA \\
\hline & $72 \mathrm{hrs}$ & $17(94.4 \%)$ & $18(100 \%)$ & 1.00 \\
\hline
\end{tabular}

In most studies, the incidence of moderate to severe post-craniotomy pain (VAS > 5) especially in the first 24 hours was high [2] [6] ranging from 50 to $80 \%$ [1]. However, in our study, most patients reported a VAS score of 1 to 3, which conventionally can be treated with simple analgesics, hence the requirement for strong opiates such as oxycodone might be reduced. Although codeine is thought to have a weaker analgesic effect compared to oxycodone, there was no statistically significant increase in the cumulative dose of codeine used compared with oxycodone from POD 0 to 3 . Again, this is likely attributable to the low VAS scores reported in our population since regular paracetamol is served as a baseline with codeine or oxycodone being given on an as needed basis.

The low incidence of severe pain postoperatively at 24 hours could be postulated to be due to scalp infiltration by the surgeon as well as the use of intravenous fentanyl intra and postoperatively as transitional analgesia, both of which might provide early, post-surgical pain relief. Nemergut suggested in his review that the incidence of severe postcraniotomy pain could be reduced with local anaesthetic infiltration by the surgeons together with transitional analgesia after intravenous remifentanil infusion intraoperatively [1].

Another factor which might explain why there was no statistically significant difference in pain scores in both groups could be due to the fact that most of our patients did not have preoperative pain. Sudheer found that patients who required opioids preoperatively were more likely to report significantly higher levels of postoperative pain hence requiring higher amounts of opioid analgesics [6]. 
In terms of pharmacokinetic profiles, the metabolism of codeine or oxycodone in the local population may play a part in explaining why we did not find a difference in the use of either drug. It is well known that only $1 \%$ of Asians compared to 7\% of Caucasians are poor metabolisers of CYP2D6 [7], which prevent them from metabolizing drugs that are substrates of this enzyme such as codeine. Codeine is metabolized to morphine, its active substrate, and poor metabolisers of codeine will experience minimal analgesia with its use. The main opioid effects of oxycodone are realized through its parent drug, although oxycodone is metabolized to noroxycodone by CYP3A4 and to oxymorphone by CYP2D6 [8], both of which have negligible analgesic effects due to the small amount produced. It is plausible that being effective metabolisers of codeine, the patients in the codeine group would be able to use codeine as effectively as oxycodone for the control of post-craniotomy pain.

Comparing codeine and oxycodone, we did not show an increase in adverse events such as sedation, respiratory depression or nausea after the use of oxycodone. Although the study may not have been powered to look at secondary objectives, there was no statistically significant difference in adverse effects between the 2 drugs, hence this could suggest the safety of prudent and titrated use of oral opioids with adequate monitoring.

\section{Conclusion}

Thus far, there has been no study comparing oral codeine with oral oxycodone in the treatment of post-craniotomy pain. Oral codeine has traditionally been used [1] due to its safety profile although many studies have found that it is inferior to the use of morphine for post-craniotomy pain. We did not show an incidence of severe pain in our patients post-craniotomy. Our study also did not show a statistically significant difference in mean VAS scores in both groups at 24 hours. Although our study did not show a difference with the use of either drug in the treatment of post-craniotomy pain, there were no significant side effects with the use of both drugs as well, hence it is safe to use either codeine or oxycodone in the treatment of post-craniotomy pain.

\section{Conflict of Interest}

The authors declare no conflicts of interest regarding the publication of this paper.

\section{Authors' Contributions}

R. M. Lee: patient recruitment, randomization, writing up of draft of paper.

B. C. L. Lim: patient recruitment, data collection.

C. T. Chong: patient recruitment, randomization.

M. P. P. Lim: study design and data analysis, patient recruitment, randomization, approving final draft of paper. 


\section{Clinical Trial Number}

NCT01672112. https://clinicaltrials.gov/.

\section{References}

[1] Nemergut, E.C., Durieux, M.E., Missaghi, N.B. and Himmelseher, S. (2007) Pain Management after Craniotomy. Best Practice \& Research Clinical Anaesthesiology, 21, 557-573. https://doi.org/10.1016/j.bpa.2007.06.005

[2] Gottschalk, A., Berkow, L.C., Stevens, R.C., Mirski, M., Thompson, R.E., White, E.D., Weingart, J.D., Long, D.M. and Yaster, M. (2007) Prospective Evaluation of Pain and Analgesic Use Following Major Elective Intracranial Surgery. Journal of Neurosurgery, 106, 210-216. https://doi.org/10.3171/jns.2007.106.2.210

[3] Lenz, H., Sandvik, L., Qvigstad, E., Bjerkelund, C.E. and Raeder, J. (2009) A Comparison of Intravenous Oxycodone and Intravenous Morphine in Patient-Controlled Postoperative Analgesia after Laparoscopic Hysterectomy. Anesthesia \& Analgesia, 109, 1279-1283. https://doi.org/10.1213/ane.0b013e3181b0f0bb

[4] Silvasti, M., Rosenberg, P., Seppala, T., Svartling, N. and Pitkanen, M. (1998) Comparison of Analgesic Efficacy of Oxycodone and Morphine in Postoperative Intravenous Patient-Controlled Analgesia. Acta Anaesthesiologica Scandinavica, 42, 576-580. https://doi.org/10.1111/j.1399-6576.1998.tb05169.x

[5] Tanskanen, P., Kyttä, J. and Randell, T. (1999) Patient-Controlled Analgesia with Oxycodone in the Treatment of Postcraniotomy Pain. Acta Anaesthesiologica Scandinavica, 43, 42-45. https://doi.org/10.1034/j.1399-6576.1999.430110.x

[6] Sudheer, P.S., Logan, S.W., Terblanche, C., Ateleanu, B. and Hall, J.E. (2007) Comparison of the Analgesic Efficacy and Respiratory Effects of Morphine, Tramadol and Codeine after Craniotomy. Anaesthesia, 62, 555-560. https://doi.org/10.1111/j.1365-2044.2007.05038.x

[7] Lurcott, G. (1999) The Effects of the Genetic Absence and Inhibition of CYP2D6 on the Metabolism of Codeine and Its Derivatives, Hydrocodone and Oxycodone. Anesthesia Progress, 45, 154-156.

[8] Smith, H.S. (2009) Opioid Metabolism. Mayo Clinic Proceedings, 84, 613-624. https://doi.org/10.1016/S0025-6196(11)60750-7 